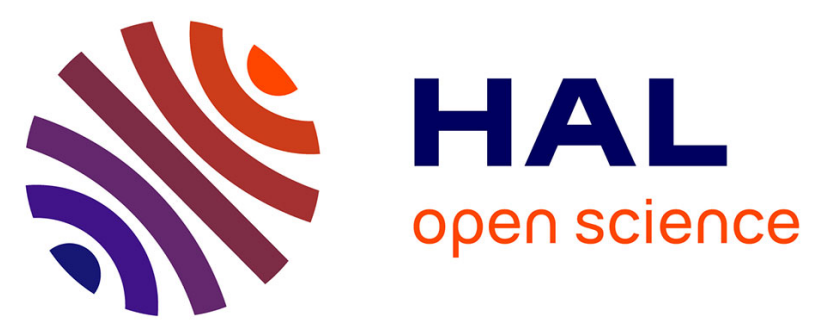

\title{
Assessing potential surrogates of macroinvertebrate diversity in North-African Mediterranean aquatic ecosystems
}

Noura Slimani, David Sánchez-Fernández, Eric Guilbert, Moncef Boumaiza, Simone Guareschi, Jean Thioulouse

\section{To cite this version:}

Noura Slimani, David Sánchez-Fernández, Eric Guilbert, Moncef Boumaiza, Simone Guareschi, et al.. Assessing potential surrogates of macroinvertebrate diversity in North-African Mediterranean aquatic ecosystems. Ecological Indicators, 2019, 101, pp.324-329. 10.1016/j.ecolind.2019.01.017 . hal-02309882

\section{HAL Id: hal-02309882 \\ https://hal.science/hal-02309882}

Submitted on 20 May 2020

HAL is a multi-disciplinary open access archive for the deposit and dissemination of scientific research documents, whether they are published or not. The documents may come from teaching and research institutions in France or abroad, or from public or private research centers.
L'archive ouverte pluridisciplinaire HAL, est destinée au dépôt et à la diffusion de documents scientifiques de niveau recherche, publiés ou non, émanant des établissements d'enseignement et de recherche français ou étrangers, des laboratoires publics ou privés. 
Assessing potential surrogates of macroinvertebrate diversity in NorthAfrican Mediterranean aquatic ecosystems

Noura Slimani a,b , $\square$, David Sánchez-Fernández c, d , Eric Guilbert a, Moncef Boumaïza b, Simone Guareschi d, Jean Thioulouse e

a UMR7179 CNRS/MNHN, Muséum National d'Histoire Naturelle, CP 50, 57 rue Cuvier, 75005 Paris, France

b Laboratory of Environment Biomonitoring (LEB), Faculty of Sciences of Bizerte, Zarzouna, University of Carthage, Tunisia

C Instituto de Ciencias Ambientales, Universidad de Castilla-La Mancha, Campus Tecnológico de la Fábrica de Armas, 45071 Toledo, Spain

d Department of Ecology and Hydrology, Regional Campus of International Importance"Campus Mare Nostrum"University of Murcia, Espinardo Campus, 30100 Murcia, Spain

e Université de Lyon, 69000 Lyon, Université Lyon 1, CNRS, UMR 5558, Laboratoire de Biométrie et Biologie Evolutive, 69622 Villeurbanne Cedex, France

https://doi.org/10.1016/j.ecolind.2019.01.

Received 8 October 2018; Received in revised form 4 January 2019;

Accepted 6 January 2019

Corresponding author at: UMR7179 CNRS/MNHN, Muséum National d'Histoire Naturelle, CP 50, 57 rue Cuvier, 75005 Paris, France. E-mail address:noura.slimanidedu.mnhn.fr(N. Slimani) . Ecological Indicators 101 (2019) 324- 329

Keywords:

Biodiversity assessment

Cross-taxon congruence

Indicator taxa

Macroinvertebrates

Inland aquatic systems

Tunisia

\section{ABSTRACT}

The need to use surrogates of biodiversity is quite relevant in threatened habitats harboring high values of

biodiversity, such as the Mediterranean aquatic ecosystems. In this study, we assess the performance of eight

macroinvertebrate groups (Coleoptera, Heteroptera, Odonata, Trichoptera, Plecoptera, Ephemeroptera,

Crustacea, and Mollusca) as surrogates of the whole aquatic

macroinvertebrate assemblage in 49 localities from

Northern Africa (Tunisia). Specifically, we aimed to test i) the

congruence of the patterns of species richness and

composition among these eight groups (at species level) in order to propose which groups could be accurate as

indicators of diversity of the whole community, and ii) if higher-taxon levels (genera or families) are suitable for

predicting overall species richness and composition in these ecosystems. In total, we found 72 families, 157

genera and 280 species. Our results show a high congruence between the patterns of species richness and 
composition of Ephemeroptera, Coleoptera (even at higher taxonomic levels, especially genus) and the whole

community. Thus, we recommend the use of these two groups as surrogates of macroinvertebrate diversity in

inland aquatic ecosystem in the study area. They can be used for both i) the rapid and inexpensive monitoring of

biodiversity in aquatic ecosystems and ii) conservational studies in order to identify areas with the highest values

of freshwater biodiversity in Mediterranean areas. Finally, high values of congruence among taxonomic levels

were found suggesting that, in general, higher taxa can be used as biodiversity surrogates for cost-effective

practical survey in Mediterranean aquatic ecosystems from Northern Africa.

\section{Introduction}

One of the main concerns for conservation biologists is trying to reduce the high rates of biodiversity loss due to human pressures (Kerr and Currie, 1995). However, most of the species on Earth have not been described so far and major gaps exist in knowledge about their distributions (Brown and Lomolino, 1998). These taxonomic and biogeographical gaps, known as Linnean and Wallacean shortfalls respectively (Lomolino, 2004), place serious limitations on the ability to conserve biodiversity in the face of the ongoing extinction crisis (Hortal et al., 2007 ). Conservation biologists and environmental managers are indeed striving tofind suitable surrogates for mapping and predicting biodiversity as an effective way to overcome this limitations (Humphries et al., 1995; Caro and O'Doherty, 1999), especially in those countries with high biodiversity levels and scarce naturalist tradition. Biodiversity surrogates are groups of organisms with a sound taxonomy that have been well surveyed in a region, and whose patterns of assemblage structure (species richness, endemism, rarity, etc..) or composition, (seecorte et al., 2017) are assumed to be indicative of similar patterns of unsurveyed taxa in the same region (Pearson, 1994). However, the validity of this assumption is rarely evaluated. In this context, researchers have traditionally used plants and/or vertebrates, especially birds, whereas arthropods have received less attention in this kind of conservation studies (Posadas et al., 2001; Cardoso et al., 2011),

despite the fact that they represent around 95\% of all known animal species (Barnes et al., 2001; Wilson, 2017). An interesting approach to include invertebrate species in the biodiversity assessments could be to consider the number of higher taxonomic groups as a surrogate of the number of local species within the same clade (or other taxonomic groups). The advantage of this approach is that the number of families or genera can be documented more rapidly than the number of species of hyperdiverse groups like invertebrates (Williams and Gaston, 1994; Caro and O'Doherty, 1999; Baldi, 2003; Villaseñor et al., 2004). The need to use surrogates of biodiversity to urgently identify areas of high biodiversity is especially relevant in aquatic ecosystem. These environments are highly diverse, since they constitute only the $0.01 \%$ of the world's water, equivalent to only $0.8 \%$ of the Earth's surface area, and support at least 100,000 species, i.e., approximately 6\% of the estimated 1.8 million described species (Dudgeon et al., 2006; Balian et al., 2008; Heino et al., 2009). Besides, freshwater ecosystems, especially those located in the Mediterranean basin, are subjected to a high 
human pressure (e.g., overexploitation; water pollution;flow modification; degradation of habitat; and invasion by exotic species: Dudgeon et al., 2006; Janssen et al., 2015), and climate change (Heino et al., 2009).

A number of studies have focused on the assessment of different taxonomic groups as biodiversity surrogates. Some of them have criticized the use offlagship species and other surrogate concepts in conservation, especially when the chosen areas are not consistently associated with high local biodiversity over space and time (Roberge and Angelstam, 2004). In an exhaustive review on freshwater ecosystems, Heino (2010)found that indicator groups and, more generally, crosstaxon congruence do not appear to be particularly relevant for conservation in the freshwater realm.Guareschi et al. (2015) found a limited concordance between assemblage patterns of macroinvertebrates and water birds in Iberian wetlands. However, other studies point out to high congruence among groups, suggesting that water beetles in Mediterranean semi-arid regions (Sánchez-Fernández et al., 2006) or snails in wetlands of Northeastern China (Guan et al., 2018 ) could be useful as effective indicator of freshwater biodiversity. In this study, we assess for thefirst time in Africa the performance of eight macroinvertebrate groups as potential surrogates of aquatic (macroinvertebrate) biodiversity. Specifically, we aimed to test i) the congruence of the patterns of species richness and composition among these eight groups (at species level) in order to identify which groups can be used more accurately as biodiversity indicators in inland aquatic ecosystem in Northern Tunisia, and ii) if higher-taxon richness are suitable for predicting overall species richness and composition in these ecosystems.

\section{Methods}

\subsection{Study area}

The study was performed in northern Tunisia (Fig. 1), a Mediterranean region located in the Maghreb (North Africa), encompassing four watersheds (Medjerda; Northwestern; Ichkeul organized within two large sub-basins: Sejnane and Joumine; and northeastern watershed. Tunisia is located in a contact zone marking the transition from the temperate humid Mediterranean climate to the dry Saharan climate (Zielhofer and Faust, 2008). The northern area of Tunisia is characterized by a typical Mediterranean climate, ranging from humid (Mogods-Kroumirie region) to sub-humid (Bizerte region). A total of forty-nine non-impacted sites were selected to include a quantitative representation of the main aquatic habitats (seeArrignon, 1976), in the study area (Fig. land Table S1 in Supplementary Material): lotic freshwater (20 sites), lentic freshwater ( 7 sites), lotic saline (17 sites)

andlentic saline waters (5 sites).

3. Biological data

For each one of the 49 selected sampling sites, faunistic compositions of eight taxonomic groups of macroinvertebrates (Crustacea, Mollusca and 6 groups of insects: Coleoptera, Heteroptera, Odonata, Trichoptera, Plecoptera, Ephemeroptera) were obtained from standardizedfieldwork. All localities were sampled in 2013, conducting the same sampling effort in each one of them. In each site, macroinvertebrates were sampled using both surber nets $(300 \mu \mathrm{m})$ and kick 
net (filet Troubleau) during twenty-five minutes across the entire habitat heterogeneity. Samples were preserved in 70\% ethanol and taken to the laboratory for identification at species level. The applied methodology is common in studies on freshwater macroinvertebrates (e.g., Picazo et al., 2012).

\section{Statistical analysis}

\subsection{Richness patterns}

Spearman rank correlations were used to evaluate the relationship among the species richness patterns of the different groups of macroinvertebrates and the Total species Richness (TSR). To avoid giving higher weight in the correlation of the groups with a greater number of species, for each taxonomic group we also calculated the Remaining Richness value (RR), defined as the total number of species at a site (of all eight groups considered) minus the number of species belonging to the considered indicator group. Finally, we also conducted Spearman correlations to explore whether the higher taxon richness (family, genus) is correlated with the species richness (and with the RR values). 4.2. Community composition patterns We used non-metric multidimensional scaling (NMDS, 'metaMDS' function in vegan) to summarize composition patterns in the aquatic macroinvertebrates dataset. We repeated the NMDS using different taxonomic levels for the entire community (family, genus and species) and within each one of the eight invertebrate groups. The analyses were performed on a biological matrix based on presence-absence data and using the Jaccard index. As some taxonomic groups do not occur in all

Fig. 1.Study area. Red dots indicate sampling localities in North Tunisia.

sites, a dummy taxon was added (when necessary), to allow the comparison among groups. A Procrustean analysis was applied to evaluate the degree and significance of community concordance among the NMDS ordinations of the different taxonomic levels and different taxonomic groups. Procrustean rotation analysis is regarded as a robust method for concordance analysis (Peres-Neto and Jackson, 2001) being frequently used to study aquatic communities (e.g.,Virtanen et al., 2009; Guareschi et al., 2015; Valente-Neto et al., 2018). Three dimensional NMDS ordinations were compared with the function 'protest' (vegan package) where the Procrustean rotation analysis was accompanied by a permutation test ( $n=9999)$. The statistic obtained is a Procrustes correlation $r$ derived from the symmetric Procrustes residual $\mathrm{m} 2(r=\sqrt{ } 1-\mathrm{m} 2)$. Congruence analyses were performed in three parts: i) comparing each order at family-genus and species level with the entire community at species levels; ii) comparing inside each order the concordance among its different taxonomic levels (only where the Order is present); and iii) using the entire community and testing the concordance among taxonomic levels. With thefirst two parts we aim to understand which group may be surrogates of others composition patters, while the last step provides useful information about taxonomic resolution useful in aquatic biodiversity assessment.

All statistical analyses were performed with R software (R Core Team, 2014), using ade4 and vegan package (http://pbil.univ-lyonl.fr/ ade4/, Thioulouse and Dray, 2007; Oksanen, 2011).

5. Results 


\subsection{Richness patterns}

A total of 72 families, 157 genera and 280 species were found in the 49 localities studied (Table 1 ). The group with highest richness was Coleoptera (117 species) followed by Mollusca (40) and Heteroptera (36). Coleoptera and Heteroptera were the most widespread groups in the study area, being present in all sampling sites (Table 2). Ephemeroptera, Mollusca, Odonata and Crustacea were absent from one type of habitat (lentic or lotic saline waters). Trichoptera species were found in 10 sites, including two types of habitat (both lotic and lentic freshwaters), while Plecoptera species were confined to freshwater lotic ecosystems appearing only in two sites (Table 2).

The richness patterns of all groups except Plecoptera were significantly correlated with the pattern of total richness (TSR) with Coleoptera showing the highest values, followed by Ephemeroptera (Table 3). In the same way, the species richness patterns of all groups but Plecoptera and Trichoptera were significantly correlated with their respective RR values, with Ephemeroptera showing the highest values (Table 3).

Among groups, the strongest correlation was found between Ephemeroptera and Mollusca, followed by Mollusca and Odonata (Table 3). The groups with highest number of significant correlations were Ephemeroptera (with all groups) and Trichoptera (with 4). However, Plecoptera were just correlated with one group, and Coleoptera with two groups ( $\mathrm{p}<0.05$; seeTable 3 ). On the other hand, the richness of families and genera considering the whole community were significantly correlated with TSR ( $r=0.845$ and $0.977 ; p<0.001$, respectively). In the same way, the richness of families and genera of any taxonomic group, were significantly correlated with TSR, their respective species richness and RR values, showing in general high spearman correlation coefficients, especially with their respective species richness values (seeTable 4).

\subsection{Community composition: patterns and congruence}

The ordination space of thefirst three axes of the NMDS including all groups presented afinal stress value of 0.15 (for both family, genus and species level). Focusing on each order separately, Heteroptera and Coleoptera families showed the highest levels of concordance with the entire macroinvertebrate community at species level ( $r=0.55$; $\mathrm{p}<0.001$; Table 5). On the other hand, Plecoptera showed the lowest level of concordance with no significant p-value. In the case of coleoptera and Heteroptera the same results were always obtained with or without using dummy taxa. At genus level Coleoptera and Heteroptera presentedthe highest level of concordance with the entire community at species level ( $r=0.69$ and $r=0.61$ respectively) while Coleoptera and Ephemeroptera obtained the best concordance at species level $(r=0.88$ and $r=0.56$, respectively; seeTable 5$)$. Focusing inside each order, the analyses were performed using only the sites where the order appears and it was not possible to proceed with Plecoptera data (just two sites with presence). In these cases Crustacea at family level presented the highest community concordance with their respective species composition $(r=0.90 ; p<0,001)$ followed by Heteroptera $(r=0.80 ; p<0,001 ;$ Table 5$)$. Overall, every order at genus level acts like a good surrogate of its community composition at species levels (minor value were obtained for Mollusca $r=0.67$ ). Finally, according 
to protest analysis, the community variation was, in all cases, significantly concordant across different taxonomic levels. However, the concordance between genus and species community assemblages was higher $(r=0.95 ; \mathrm{p}<0.001)$ than the concordance between family and species community $(r=0.69 ; \mathrm{p}<0.001)$.

\section{Discussion}

This is thefirst study addressing the potential use of biodiversity surrogates in North-African inland aquatic ecosystems. One of the main strengths of this study is the wide taxonomic spectrum considered. Unlike other studies (e.g.Heino et al., 2003; Bilton et al., 2006; Guareschi et al., 2015), we consider here the main macroinvertebrate groups (excepting Diptera) in Mediterranean freshwater ecosystems, both in terms of species richness and abundance (seeTierno de Figueroa et al., 2013).

The high correlation values found between the species richness of the whole community and the species richness of most of the considered taxonomic groups, especially Coleoptera $(r=0.847)$ and

Ephemeroptera $(r=0.730)$ suggest that at least these groups can be used as effective surrogates of the whole macroinvertebrate community, being congruent with the results found insánchez-Fernández et al. (2006) and Bilton et al (2006). Coleoptera and, even if in a less way Ephemeroptera, have been already stressed as surrogate of aquatic macroinvertebrate richness in freshwater ecosystems belonging to the Spanish National Parks (Guareschi et al., 2012).

Nevertheless, examining the correlation between species richness patterns is only one of the possible ways to evaluate biodiversity indicators (Kati et al., 2004), and these results only partially match with those obtained with the community composition assessment. Previous studies suggest that strong concordance between multiple organism groups should be indicated by r-values > 0.7 (e.g.,Heino, 2010). In this case, just Coleoptera at species level showed a r-value higher than 0.7 , being Coleoptera, Heteroptera and Ephemeroptera (at any

Table 1

Number of families, genera and species of the eight taxonomic groups recorded

in the study area.

、.

Families Genera Species

‥

‥

Coleoptera (Col) 1251117

Heteroptera (Het) $1319 \quad 36$

Ephemeroptera (Eph) $819 \quad 24$

Plecoptera (Ple) 61016

Odonata (Odo) 71419

Trichoptera (Tri) 6918

Mollusca (Mol) 132740

Crustacea (Cru) 78810

Total 72157280

、.

taxonomic resolution) the taxonomic groups whose community composition showed the highest levels of concordance with the entire community at species level.

Thus, it seems that Coleoptera at species level stands out in both 
richness and (even if in less minor) composition assessments. The use of Coleoptera as surrogate shows some important advantages, as it encompasses the gradient of environmental heterogeneity in semi-arid Mediterranean regions, i.e., they are present in all localities irrespec-

tive of the type of habitat, showing similar results in each type of habitat separately (see Table sl in Suplementary Material). However, the correlation values when excluding beetles species from the complete pool (RR), although significant, falls from 0.847 to 0.399 (Table 3), suggesting that the high species richness of this group is biasing the obtained results with the whole community. In the same way, the results on congruence of community composition were conducted only considering the whole community and not separately with RR due to methodological problems to compare values when some species groups are missing. Besides, excepting Ephemeroptera, the congruence among richness patterns of the different groups was weak in most of the cases. This result was similar to those found byHeino et al. (2003)across 110 headwater streams in Finland. Patterns of Coleoptera species richness just correlated significantly with patterns of species richness of two groups (Heteroptera and Ephemeroptera). These issues call in question in some degree the performance of water beetles as unique surrogate of biodiversity in Mediterranean freshwater ecosystems (seeHeino, 2010), and suggest its use in combination with others like Ephemeroptera and Heteroptera as a combined effective strategy.

On the other hand, the correlation values between family and genus levels with TSR were high, suggesting that, in general, the higher taxa (both genera and families) could be used as biodiversity surrogates for cost-effective practical survey. Besides, we observed that assemblage composition patterns among taxonomic levels are concordant and significant, with relevant values of significance (minor value of $r=0.69$ ). In this context, the community composition even at family level presented a significant level of concordance with the community composition at species level. The r-values obtained between groups at family level and the whole community at species level (0.23-0.55) may be considered quite similar to those obtained byDolph et al. (2011) studying concordance between fish and macroinvertebrate

Table 2

Number of sites with the presence of each group in the different types of habitat.

, 冫

Lotic-freshwater

$(\mathrm{n}=20)$

$\cdots$

Lentic-freshwater

$(\mathrm{n}=7)$

$\cdots$

‥

Lotic-saline

$(\mathrm{n}=17)$

$\cdots$

$\cdots$

Lentic-saline

$(\mathrm{n}=5)$

‥

ㄴ

All sites 
․

Coleoptera 20177549

Heteroptera $2017 \quad 7 \quad 5 \quad 49$

Ephemeroptera $20 \quad 15 \quad 7 \quad 0 \quad 42$

Plecoptera 200000

Odonata $17 \quad 7 \quad 0 \quad 125$

Trichoptera $8 \begin{array}{lllll} & 2 & 0 & 0 & 10\end{array}$

Mollusca $15 \quad 1 \quad 5 \quad 0 \quad 21$

Crustacea $12 \quad 5 \quad 0 \quad 118$

‥

Table 3

Results of pairwise spearman correlation coefficients for the species richness of the eight groups of taxa studied (49 sampling sites).TSR: Total Species Richness; RR:

Remaining Richness. See codes of the groups inTable $2 . * p<0.05, * \star p<$ $0.01, * \star \star \mathrm{p}<0.001$.

Col Het Eph Ple Odo Tri Mol Cru TSR RR

‥

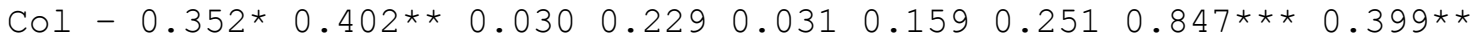

Het $-0.464 * * * 0.319 * 0.083 \quad 0.160 \quad 0.1190 .255 \quad 0.539 * * * 0.407 * *$

Eph $-0.316 * 0.400 * * 0.493 * * * 0.525 * * * 0.317 * 0.730 * * * 0.610 * * *$

Ple $-0.1500 .471 * * * 0.2470 .0620 .2860$.

Odo $-0.369 * * 0.519 * * * 0.207 \quad 0.477 * * * 0.394 * *$

Tri $-0.487 * * * 0.1660 .344 * 0$.

Mol $-0.2040 .524 * * * 0.365 * *$

Cru $-0.366 * * 0.297 *$

Table 4

Spearman correlation coefficient within each group at different taxonomic le-

vels (families, genera and species), with the Total species Richness (TSR) and

the remaining richness of each group (RR) (49 sampling sites). *p < 0.05 , $\star \star \mathrm{p}<0.01, * \star \star \mathrm{p}<0.001$.

S COl TSR RR_COl

․

F Col $0.842 * \star * 0.733 * * * 0.368 * *$

G-Col $0.984 * \star * 0.793 * \star * 0.334 *$

、.

S_Het TSR RR_Het

、

F Het $0.763 * * * 0.393 * * 0.302 *$

G-Het $0.926 * \star \star 0.481 * \star \star 0.365 * \star$

、、

S_Eph TSR RR_Eph

$\cdots$

F_Eph $0.892 \star \star \star 0.550 * \star \star 0.430 * \star$ 


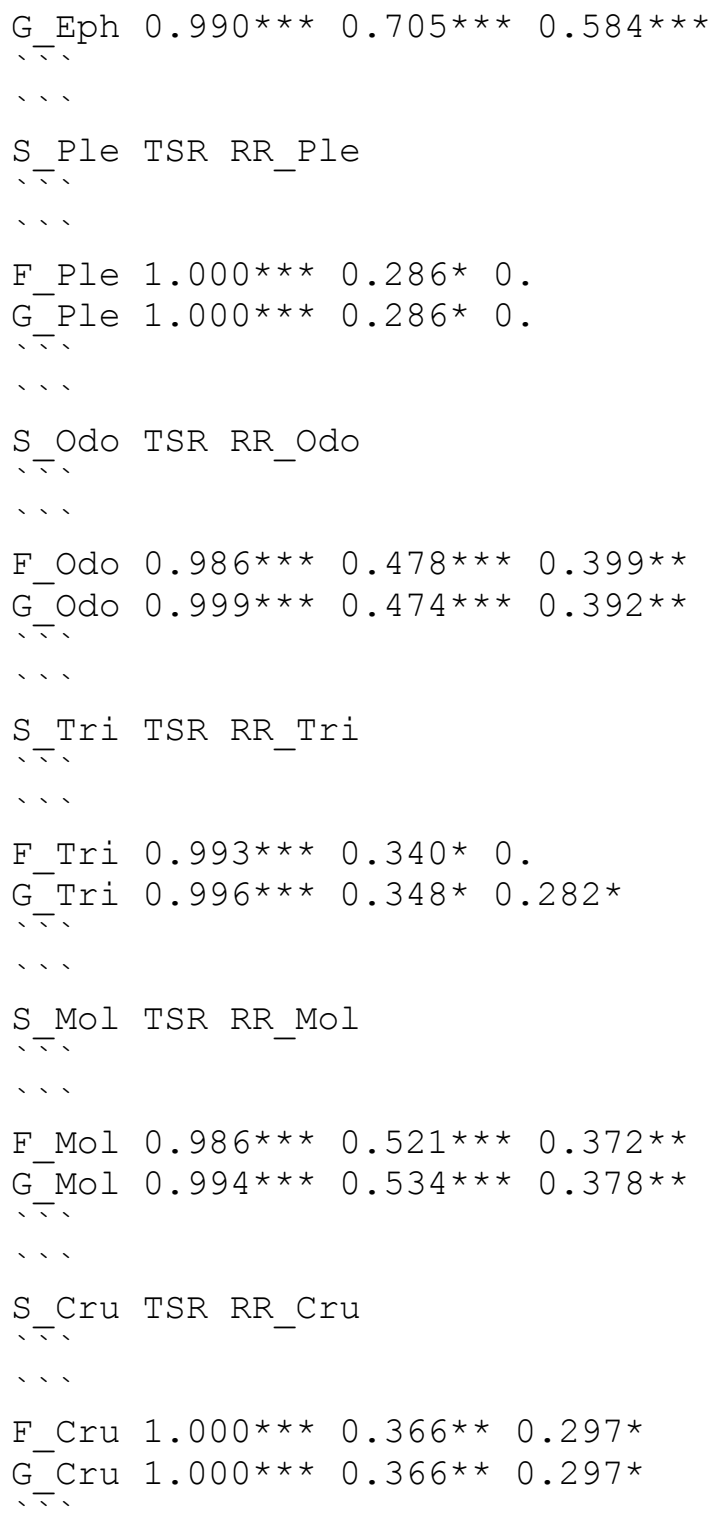

Table 5

Concordance among assemblages of each group at different taxonomic levels and A) the whole dataset at species level and; B) the species of each specific

taxonomic group (only in sites where species of each group were detected).

Concordance based on Protest. It is shown the Procrustean correlation (r) and

the associated $\mathrm{m} 2$ statistic. Significances of the Procrustean statistic were cal-

culated from randomisation tests (9999 permutations). F = family level; $\mathrm{G}=$ genus level; $\mathrm{S}=$ species level. ${ }^{\star} \mathrm{p}<0.05,{ }^{*} \mathrm{p}<0.01, \star \star \star \mathrm{p}<0.001$. $\mathrm{AB}$

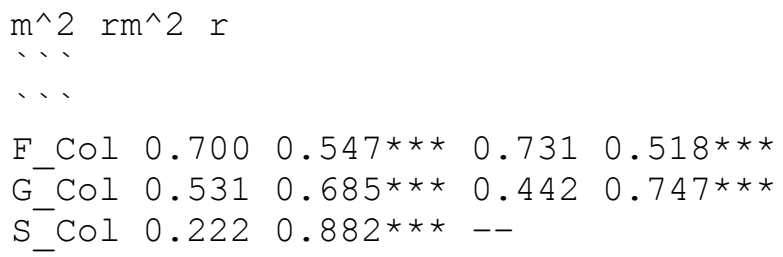




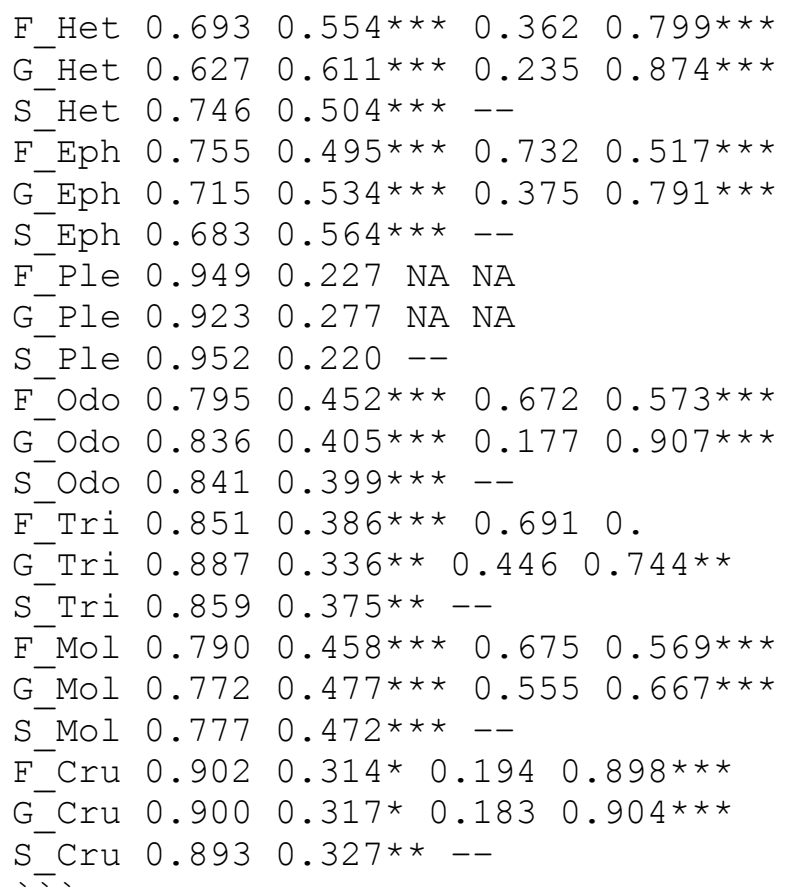

communities in North American rivers andGuareschi et al. (2015) studying concordance among waterbirds and macroinvertebrates in Mediterranean wetlands. However, the highest level obtained between assemblages at genus and species levels, seems to stress genus level as the ideal compromise between classification effort and gathered information. The identification of individuals at genus level, generally possible at their last larvae stage or with adults, can be conducted using

exclusively morphological characters (see e.g.Tachet et al, 2010). Nevertheless, among adult insects, only the majority of Coleoptera and Heteroptera are strictly aquatic and they generally represent the most frequently recorded taxonomic groups in lentic systems (e.g., Nicolet et al., 2004; Guareschi et al., 2015). Valente-Neto et al. (2018)also recommend EPT taxa (Ephemeroptera, Plecoptera and Trichoptera) at genus level as the best indicator group for monitoring the effects of riparian vegetation loss on aquatic biodiversity in Neotropical streams. Thus, considering all results together, we propose the use of

Ephemeroptera in combination with Coleoptera both at genus level as the best surrogate of biodiversity macroinvertebrates in inland aquatic ecosystems of Tunisia. Besides, it is important to note that any potential

surrogate of biodiversity must cover a reasonably wide geographic range and occur in a broad range of habitat types (Caro and o'Doherty, 1999 ), and this is the case of both Ephemeroptera and Coleoptera (Tachet et al., 2010). In sum, we recommend the use of higher taxa as surrogates for the rapid assessment of aquatic biodiversity only when accurate information on species level (rare, endemic or endangered species) is not available (most of the cases working with invertebrates, especially in Africa).

This proposal of biodiversity surrogates can be used i) for the rapid and inexpensive monitoring of biodiversity in aquatic ecosystems of Mediterranean areas and ii) for conservational studies in order to identify areas with the highest values of biodiversity in which the aquatic environment has been or will be threatened (Dudgeon et al., 2006; Vörösmarty et al., 2010; Chadwick, 2010; Tierno de Figueroa 
et al., 2013). Indeed, thefivefirst sites ordered by the criteria of complementarity using the data of Coleoptera and Ephemeroptera at genus level, encompassed 172 species (62\% of the total), which is interesting for conservational purposes and could be useful for future biomonitoring programmes and biodiversity research. Ourfindings provide a relevant contribution to the task of searching areas of high aquatic biodiversity in poorly sampled areas such as North Africa, as well as to explore congruencies among taxonomic groups in inland aquatic ecosystems from this area. However further studies in other areas of Tunisia and other North African states are recommended to improve and update the distribution mainly on water beetles and mayflies (also from the whole macroinvertebrate community in some localities) to complement and validate our main results. Thus, different stakeholders (e.g. conservationists, environmental consultants, natural resource managers, universities) may directly benefit from thesefindings establishing thefirst practical information on biodiversity surrogate selection in these aquatic systems.

Acknowledgements

DS-F was supported by a post-doctoral contract funded by the Universidad de Castilla-La Mancha and the University of Murcia.

Appendix A. Supplementary data

Supplementary data to this article can be found online at https://doi.org/10.1016/j.ecolind.2019.01.017.

References

Arrignon, J., 1976. Aménagement écologique et piscicole des eaux douces. In: Bordas:

Ecologie fondamentale et appliquée, pp. 321.

Baldi, A., 2003. Using higher taxa as surrogates of species richness: a study based on 3700

Coleoptera, Diptera, and Acari species in Central-Hungarian reserves.

Basic Appl.

Ecol. 4, 589-593.

Balian, E.V., Segers, H., Lévêque, C., Martens, K., 2008. The freshwater animal diversity

assessment: an overview of the results. Hydrobiologia 595, 627-637.

Barnes, R.S.K., Calow, P., Olive, P.J.W., Golding, D.W., Spicer, J.I., 2001. In: The

Invertebrates: A Synthesis, Oxford, pp. 512.

Bilton, D.T., Mcabendroth, L., Bedford, A., Ramsay, P.M., 2006. How wide to cast the net?

Cross-taxon congruence of species richness, community similarity and indicator taxa

in ponds. Freshwater Biol. 51, 578-590.

Brown, J.H., Lomolino, M.V., 1998. Biogeography, second ed. Sinauer

Associates,

Sunderland, Massachusetts USA, pp. 691.

Cardoso, P., Erwin, T.L., Borges, P.A., New, T.R., 2011. The seven impediments in in-

vertebrate conservation and how to overcome them. Conserv. Biol. 144

(11),

2647 - 2655 . 
Caro, T.M., O'Doherty, G., 1999. On the use of surrogate species in conservation biology.

Conserv. Biol. 13, 805-814.

Chadwick, D.H., 2010. Silent streams. Natl. Geogr. Mag. 217, 116-128. Corte, G.N., Checon, H.H., Vieira, D.C., Fonseca, G., Amaral, A.C.Z., 2017. Cross-taxon

congruence in benthic communities: searching for surrogates in marine sediments.

Ecol. Ind. 78, 173-182.

Dolph, C.L., Huff, D.D., Chizinski, C.J., Vondracek, B., 2011.

Implications of community

concordance for assessing stream integrity at three nested spatial scales in Minnesota,

USA. Freshwater Biol. 56, 1652- 1669.

Dudgeon, D., Arthington, A.H., Gessner, M.O., Kawabata, Z.-I., Knowler, D.J., Lévêque,

C., Naiman, R.J., Prieur-Richard, A.-H., Soto, D., Stiassny, M.L.J., Sullivan, C.A.,

2006. Freshwater biodiversity: importance, threats, status and conservation chal-

lenges. Biol. Rev. 81, 163-182.

Guan, Q., Liu, J., Batzer, D.P., Lu, X., Wu, H., 2018. Snails (Mollusca:

Gastropoda) as

potential surrogates of overall aquatic invertebrate assemblage in

wetlands of

Northeastern China. Ecol. Ind. 90, 193-200.

Guareschi, S., Gutiérrez-Cánovas, C., Picazo, F., Sánchez-Fernández, D., Abellán, P. ,

Velasco, J., Millán, A., 2012. Aquatic macroinvertebrate biodiversity: patterns and

surrogates in mountainous Spanish national parks. Aquat. Conserv: Mar.

Freshwater

Ecosyst. 22, 598-615.

Guareschi, S., Abellán, P., Laini, A., Green, A.J., Sánchez-Zapata, J.A., Velasco, J.A.,

Millán, 2015. Cross-taxon congruence in wetlands: assessing the value of waterbirds

as surrogates of macroinvertebrate biodiversity in Mediterranean Ramsar sites. Ecol.

Ind. 49, 204-215.

Heino, J., 2010. Are indicator groups and cross-taxon congruence useful for predicting

biodiversity in aquatic ecosystems? Ecol. Ind. 10, 112-117.

Heino, J., Muotka, T., Paavola, R., Paasivirta, L., 2003. Among-taxon congruence in

biodiversity patterns: can stream insect diversity be predicted using single taxonomic

groups? Can. J. Fish. Aquat. Sci. 60, 1039- 1049.

Heino, J., Virkkala, R., Toivonen, H., 2009. Climate change and

freshwater biodiversity:

detected patterns, future trends and adaptations in northern regions.

Biol. Rev. 84,

$39-54$.

Hortal, J., Lobo, J.M., Jiménez-Valverde, A., 2007. Limitations of biodiversity databases:

case study on seed-plant diversity in Tenerife, Canary Islands. Conserv Biol 21,

$853-863$. 
Humphries, C.J., Williams, P.H., Vane-Wright, R.I., 1995. Measuring biodiversity value

for conservation. Ann. Rev. Ecol. Syst. 26, 93-111.

Janssen, A.B., Arhonditsis, G.B., Beusen, A., Bolding, K., Bruce, L., Bruggeman, J.,

Couture, R.M., Downing, A.S., Elliott, J.A., Frassl, M.A., Gal, G., Gerla, D.J., Hipsey,

M.R., Hu, Fenjuan, Ives, S.C., Janse, J.H., Jeppesen, E., Jöhnk, K.D., Kneis, David,

Kong, X., Kuiper, J.J., Lehmann, M.K., Lemmen, C., Özkundakci, Deniz, Petzoldt, T.,

Rinke, K., Robson, B.J., Sachse, R., Schep, S.A., Schmid, M., Scholten, H., Teurlincx,

S., Trolle, D., Troost, T.A., Van Dam, A.A., Van Gerven, L.P.A., Weijerman, M., Wells,

S.A., Mooij, W.M., 2015. Exploring, exploiting and evolving diversity of aquatic

ecosystem models: a community perspective. Aquat. Ecol. 49, 513-548.

Kati, V., Devillers, P., Dufrêne, M., Legakis, A., Vokou, D., Lebrun, P., 2004. Testing the

value of six taxonomic groups as biodiversity indicators at a local

scale. Conserv. Biol.

$18,667-675$.

Kerr, J.T., Currie, D.J., 1995. Effects of human activity on global extinction risk. Conserv.

Biol. 9, 1528- 1538 .

Lomolino, M.V., 2004. Conservation biogeography. In: Lomolino, M.V., Heaney, L.R.

(Eds.), Frontiers of Biogeography: New Directions in the Geography of Nature.

Sinauer Associates, Sunderland, Massachusetts, pp. 293-296.

Nicolet, P., Biggs, J., Fox, G., Hodson, M.J., Reynolds, C., Whitfield, M., Williams, B.,

2004. The wetland plant and macroinvertebrate assemblages of temporary ponds in

England and Wales. Biol. Conserv. 120, 261-278.

Oksanen, J., 2011. The Vegan package. Version 1. 17-11. Community Ecology Package.

Documentation for R: a language and environment for statistical

computing.

Pearson, Q.M., 1994. Treatment techniques for adult female survivors of childhood sexual

abuse. J. Couns. Dev. 73, 32-37.

Peres-Neto, P.R., Jackson, D.A., 2001. How well do multivariate data sets match? The

advantages of a Procrustean superimposition approach over the Mantel

test.

Oecologia 129, 169-178.

Picazo, F., Bilton, D.T., Moreno, J.L., Sánchez-Fernández, D., Millán, A., 2012. Water

beetle biodiversity in Mediterranean standing waters: assemblage

composition,

environmental drivers and nestedness patterns. Insect Conserv. Divers. 5, 146-158.

Posadas, P., Miranda, D.R., Crisci, J.V., 2001. Using phylogenetic

diversity measures to

set priorities in conservation: an example from southern South America.

Conserv. 
Biol. 15, 5- 1334.

R Development Core Team, 2014. R: A Language and Environment for Statistical

Computing. R Foundation for Statistical Computing, Vienna, Austria. URLhttp: / /

http://www.R-project.org.

Roberge, J.M., Angelstam, P., 2004. Usefulness of the umbrella species concept as a

conservation tool. Conserv. Biol. 18, 76-85.

Sánchez-Fernández, D., Abellán, P., Mellado, A., Velasco, J., Millán, A., 2006. Are water

beetles good indicators of biodiversity in Mediterranean aquatic

ecosystems? The

case of the Segura river basin (SE Spain). Biodivers. Conserv. 15, 45074520 .

Tachet, H., Richoux, P., Bournaud, M., Usseglio-Polatera, P., 2010.

Invertébrés d'Eau

Douce (2nd corrected impression). CNRS editions, Paris, pp. 607.

Thioulouse, J., Dray, S., 2007. Interactive multivariate data analysis in $R$ with the ade

and ade4TkGUIpackages. J. Stat. Software 22 (5), 1-14.

http: //wWw.jstatsoft.org/

v22/i05.

Tierno de Figueroa, J.M.T., López-Rodríguez, M.J., Fenoglio, S., SánchezCastillo, P.,

Fochetti, R., 2013. Freshwater biodiversity in the rivers of the

Mediterranean Basin.

Hydrobiologia 719, 137-186.

Valente-Neto, F., Rodrigues, M.E., de Oliveira Roque, F., 2018. Selecting indicators based

on biodiversity surrogacy and environmental response in a riverine

network: Bringing

operationality to biomonitoring. Ecol. Ind. 94, 198-206.

Villaseñor, J.L., Ibarra-Manriquez, G., Meave, J.A., 2004. Higher taxa as surrogates of

plant biodiversity in a megadiverse country. Conserv. Biol. 19, 232-238. Virtanen, R., Ilmonen, J., Paasivirta, L., Muotka, T., 2009. Community concordance be-

tween bryophyte and insect assemblages in boreal springs: a broad-scale study in

isolated habitats. Freshwater Biol. 54, 1651-1662.

Vörösmarty, C.J., McIntyre, P.B., Gessner, M.O., Dudgeon, D., Prusevich, A., Green, P.,

Glidden, S., Bunn, S.E., Sullivan, C.A., Reidy Liermann, C., Davies, P.M., 2010. Global

threats to human water security and river biodiversity. Nature 467, 555561 .

Williams, P.H., Gaston, K.J., 1994. Measuring more of biodiversity: can higher taxon

richness predict wholesale species richness? Conserv. Biol. 67, $211-217$. Wilson, E.O., 2017. Half-earth: Our Planet's Fight for Life. WW Norton, New York.

Zielhofer, C., Faust, D., 2008. Mid-and Late Holocenefluvial chronology of Tunisia. Quat.

Sci. Rev. 27, 580-588.

、. 